\title{
Research and Practice on Innovative Training Mode of Science and Engineering Graduate Students \\ Hongmei Zhang ${ }^{1, \mathrm{a}^{*}}$,Xingdong Peng ${ }^{1, \mathrm{~b}}, \mathrm{Na} \mathrm{Li}^{1, \mathrm{c}}$ and Hongyang Zhao ${ }^{1, \mathrm{~d}}$
}

\author{
${ }^{1}$ University of science and technology Liao ning,An shan,Liao ning,China

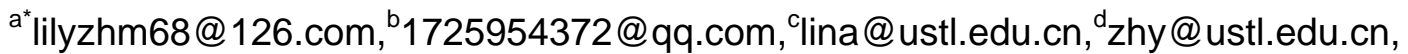 \\ *Hong-mei Zhang
}

\begin{abstract}
Keywords:Innovative practice ability training,Postgraduate training model,Construction of postgraduate tutor team,Curriculum system construction.

Abstact:Taking some high level research universities in China as samples, through serious research, we found that many domestic famous colleges and universities put forward a lot of creative mode of graduate cultivation on the basis of summarizing their own graduate training mode. Our task group have studied systematically on our university's graduate project -"The Research and Practice on the Cultivation of Innovative Talents Based on the Specialty of Material Processing" which focus on the four cultivation mode of science and engineering graduate students aspects:innovative practice ability training of graduate students, innovative postgraduate training model, postgraduate curriculum system construction, construction of postgraduate tutor team.
\end{abstract}

\section{理工类研究生创新培养模式的研究与实践}

\author{
张红梅 ${ }^{1, a^{*}}$ 彭兴东 ${ }^{1, b}$ 李娜 ${ }^{1, c}$ 赵红阳 ${ }^{1, d}$ \\ 1 辽宁科技大学材料成型及控制工程系, 千山区, 鞍山, 辽宁, 中国 \\ a*lilyzhm68@126.com, ${ }^{\mathrm{b}} 1725954372 @ q q . c o m,{ }^{\mathrm{c}} 15938489 @ q q . c o m,{ }^{\mathrm{d}} 35057415 @ q q . c o m$, \\ *张红梅
}

关键词: 创新实践能力培养;培养模式;课程体系建设; 导师队伍建设

摘要: 以国内一些高水平研究型大学为样本, 通过认真的梳理, 我们发现很多国内知名高校 在总结自身丰富的研究生培养模式的基础上, 提出了很多具有启发意义的研究生培养创新模 式。我们课题组就 “基于材料加工专业特色研究生创新人才培养的研究与实践” 这个我校研 究生创新项目课题, 针对研究生创新实践能力培养、创新研究生培养模式、研究生课程体系 建设、研究生导师队伍建设等理工类研究生培养模式的四个具体方面进行了深入系统地的研 究。

\section{1 引言}

近十年来, 随着国民经济、社会环境的不断发展, 研究生教育规模的快速扩大, 学位类 型、培养模式日趋多样的今天, 探讨如何有效保证研究生教育质量, 提升研究生培养水平、 优化研究生培养模式, 满足我国经济社会发展对高层次人才的需求显得尤为重要。《国家中 长期教育改革和发展规划纲要（2010 2020）》（后面简称《教育规划纲要》）[1]强调创新 人才培养模式“要适应国家和社会发展需要, 遵循教育规律和人才成长规律, 深化教育教学 改革, 创新教育教学方法, 探索多种培养方式, 形成各类人才辈出、拔尖创新人才不断涌现 的局面”。随着学科结构逐步完善, 形成了学科门类较齐全、培养模式多样化、多层次、多 类型的学位与研究生教育体系。为了保障研究生的培养质量, 研究生培养机制改革正在全国 各有关高校予以探索和实践, 并取得了阶段性成果, 亟待深入研究与创新实践。 
辽宁科技大学是一所以工学为主, 涵盖工学、理学、经济学、管理学、文学、法学、艺 术等七大门类的多科性大学, 学校注重加强科学研究, 科研实力和水平不断提高。在这座综 合性的大学中, 对研究生培养非常重视, 学校一直以来力求每个研究生的差异和特点进行教 学改革及采取多方面的举措, 培养专业基础扎实、具备创新能力、分析与思考能力的复合型 人才是学校一直以来努力培养的目标。近年来, 学校鼓励教师积极开展研究生教育改革创新 项目, 特别是理工类研究生培养模式创新方面。我们课题组就“基于材料加工专业特色研究 生创新人才培养的研究与实践”课题开展了研究。我们以 2002 年来我国“985”中 20 所高水平 研究型大学为样本, 对上述各大学研究生培养模式相关学术论文以及重要会议进行了文献检 索。通过认真的梳理, 我们发现很多国内许多知名高校在总结自身丰富的研究生培养模式的 基础上, 提出了很多具有启发意义的研究生培养创新模式, 为我们提供了宝贵经验[2 5]。我 们课题组认为, 理工科的研究生的培养模式创新要从注重创新实践能力培养、创新培养模式、 课程体系建设改革、导师队伍建设等四个主要方面进行了研究, 深入系统地思考研究生培养 模式的完善与提升。

\section{2 研究生创新实践能力培养}

刘延东同志在纪念《中华人民共和国学位条例》实施 30 周年纪念大会上的讲话: “研究生培 养机制改革的灵魂是担负起造就高层次人才和支撑自主创新的历史重[6]。创新是灵魂, 科学 研究主导是核心。创新不仅是一个民族进步的灵魂和国家兴旺发达的不竭动力, 也是引领时 代发展的风向标和潮流。作为国家知识创新基础的高等教育, 特别是最高层次的研究生教育, 在完善国家创新体系中具有特别意义。为此, 作为创新人才培养的研究生教育, 应该强调对 研究生创新精神、创新思维、创新能力的挖掘和培养。这是时代、社会发展的需要, 也是教 育自身发展的需要。

研究生教育是国家高等教育创新体系的重要组成部分, 我国研究生培养模式改革的重要方向 之一是建立研究生创新实践能力的培养机制。以实践、创新为导向的优化整合机制、完善研 究生创新能力养成培养机制是现阶段研究的热点。《教育规划纲要》中指出, 创新人才培养 模式必须注重知行统一、学思结合。面向实践、注重创新的人才培养导向, 是将创新实践能 力养成作为优化、改革研究生培养模式的重中之重。华南理工大学陈铁群等[3]提出了“适应 规模发展、提高创新能力, 发挥产学优势、参与市场竞争, 加快人才成长”的研究生培养新 模式。方祯云[7]以“重庆大学研究生创新实践基地”为例, 从研究生管理模式、研究生创新基 金管理等方面介绍了研究生培养模式。研究生教育就是要保证研究生“创新能力” 的养成, 使 学生形成独立的科学研究能力与学术思维导向。

综上所述, 创新是研究生培养机制改革的起点和终点, 是灵魂; 创新从科研实践和探索 中获得, 科研是创新的温床, 要创新就需走科研道路; 要促进研究生科研, 必须建立导师负 责制。

\section{3 创新研究生培养模式}

\section{1 立足本土、面向世界的研究生国际化教育模式}

随着经济全球化时代的到来, 传统的强调研究生“创新能力强、实践能力强” 的二维素质培养 目标已不能满足对高素质人才的要求, 还需加强研究生 “国际化能力和文化素质” 的要求。《教 育规划纲要》第 48 条提出, 要“开展多层次、宽领域的教育交流与合作, 提高我国教育国 际化水平” [1] “借鉴国际上先进的教育理念和教育经验, 促进我国教育改革发展, 提升我国教 育的国际地位、影响力和竞争力”。为此, 必须拓展研究生培养目标, 树立研究生三强一高” 思维素质培养目标即“创新能力强、实践能力强、国际化能力强、文化素质高”。通过研究生 
国际化能力培养, 彰显研究生国际学术思维、国际学术交流的能力。南京航空航天大学[8] 从 2009 年开始实施研究生国际化教育试点以来, 经过几年的探索与实践, 形成了 “立足本土、 面向世界”的研究生国际化教育模式，并取得了良好的成效，具有非常好的推广价值。立足 本土, 就是在传统的国际化教育方式的基础上, 通过构建研究生国际化培养体系, 使大多数 学生不出国门就接受国际化教育, 使少数学生能够接受的昂贵的国际化教育惠及到大部分学 生。创新培养理念、突破传统模式、接轨国际一流, 全面推进研究生国际化教育具有十分重 要的意义。

借鉴国际一流大学、一流学科的课程体系构建本校特色、世界前沿的研究生国际化课程。经 过广泛深入的实际和文献调研, 我们得出结论: 美国、澳大利亚的研究生教育比较强调创新 能力的培养; 欧洲和日本的研究生教育注重实践能力的培养。这些国外的研究生教育经验值 得我们借鉴，这也是开展“立足本土、面向世界”的研究生国际化教育的基础。

\section{2 跨学科研究生培养是我国现有培养模式的有益补充}

近年来, 学科融合、交叉特征更加显著, 特别是新兴前沿学科研究, 更要求研究人员具 有交叉学科教育背景、并具备较强的跨学科科研实践能力。特别是近几年来学科组群建设方 面的研究也由传统单一学科内部分析向跨领域多学科综合研究转变。何刚等[9]分析指出: 科 研人员合作意识不强、学科融合的结构层次不完善, 以及学科包容性、开放性不够, 是制约 我国研究生交叉学科培养体系形成的几个关键方面。跨学科研究生培养是对我国现有培养模 式的有益补充, 应该加以重视并发展。

\section{4 创新研究生课程体系建设}

\section{1 课程体系建设重要性}

随着社会的发展, 人们逐渐认识在研究生培养过程中, 应根据学生的知识结构来制定培养方 案, 从而设置课程体系, 加强现代科技知识的掌握, 并将所学新知识及时应用到工作中去, 以提高其实践技能。课程教学是研究生培养工作的基础, 改进研究生“知识传授”的教学方式, 拓展研究生的知识结构, 注重业务综合素质和知识获取能力的培养, 是提高研究生培养质量 的重要举措。

随着时代的发展, 各行各业对从业者的素质要求越来越高, 特别是一些专业化程度很高的职 业比一般的职业对特定知识、技能有更加严格的要求。研究生除了应掌握专业知识外, 还应 更多掌握相关领域的知识和技能, 注重科学教育与人文教育的结合, 使专业人员具有更高的 自律性和忘我的职业精神。比如, 在全日制材料加工专业学位研究生培养过程中, 可以适当 加入经济、管理、市场、这些课程可以培养专业学位研究生职业素质, 为以后走向工作岗位 打下坚实的基础。

\section{2 研究生课程体系创新}

研究生课程体系创新是我国研究生教育改革的一项非常重要任务。目前很少针对不同课程内 容采取不同教学方式, 课堂讲授多、教学辅导少, 讨论交流少; 重视知识的传授, 缺少对研 究生批判思维、自主学习能力的培养。这种教学方法使得学生无法实现教学互动, 无法实现 有效的教学目的, 学生始终处于被动接受学习的地位在研究生培养过程中。传统的教学观念 认为, 把学生带向学术前沿就是最佳的课堂教学; 传统的教学论教条认为把最先进、最系统 的知识传授给学生才是最好的教学方式。研究生教育就是要传授最前沿的知识, 而不考虑学 生真正的兴趣和承受能力。此时学生只是被动地接受教师传授的课堂知识, 这是一种单向的 灌输式教学, 从而无法培养具有创新活力的人才。

我们课题组教师在多年教学中经常发现, 在实践中, 教育者总希望把自己整理出的知识直接 传授给学生, 直接把学生推向学术前沿, 这种教学方法是不切实际的, 因为它忽视了学术研 
究需要的经验积累过程, 忘记了知识不可能速成, 这种设想是注入式教学思想的根源, 学生 在接受知识时绝大多数都是表面上理解了, 并没有内化为自己的知识, 更无法指导自己的实 践[10]。而老师想当然地认为学生理解了就可能是掌握了, 知道了就可以运用了。在进行了 系统的知识讲授后, 同学确实都理解了但是一旦要将这些知识变成指导实践的方法或能力, 一遇到实际问题需要解决时, 这些知识全用不上。这说明此时接受式的理解仅仅是表层, 没 有深刻理解或应用以实际, 要促进学生从“知”向“行”的转变。在课程设计上, 课堂讲解上就 必须从抛弃传统的传授最先进的、最系统的知识开始, 从传授那些最适合的知识、最需要的 知识也即最有用的知识出发, 这就要求课堂教学增加针对性和实用性, 突出个性化教学, 在 最适合和最需要上下工夫。研究生课堂教学必须让学生从“知道”到“会做”“怎么做”的转变, 只有达到了“能做”“会做”这个层次后学生才是真正掌握知识, 学到了真正知识。

2016 年 2 3 月, 我们课题组在澳大利亚伍伦贡大学访学, 并系统对他们研究生教学进行 实际考察与研究, 发现他们的研究生教学具有三个突出特点: 一是教师作用在引导而非具体 的教, 老师上课速度很快, 信息量巨大; 二是学生是课堂主角, 教师只是引导和辅导者; 三 是学生学习主要时间是在课下, 课堂主要用于讨论交流, 普遍采用小组学习和集体讨论, 学 生组织能力非常强; 四是每门课的成绩是由几个大作业成绩、小组讨论成绩以及最后考试成 绩综合而成。我们认为这种教学方式能够调动学生的潜能、培养学生实际研究能力; 学生受 到的训练不仅是科研方法的训练, 更重要的是合作能力、讲演能力和组织能力训练, 这种教 学方式更容易培养学生的研究能力和创造力。

\section{5 研究生导师队伍建设}

我国研究生培养实行的是导师负责制, 导师的思维方式、学术见解和研究方法必定对学 生的发展产生深远影响。中国人民大学吴晓求[4]结合高校教学、培养实际提出, 应从培养过 程、导师权责、资助体系和管理模式等方面加强研究生培养。浙江大学杨卫[5]认为, 要坚持 “导师主责、科研主导、协同创新、激励相容” 四个研究生培养基本原则, 加强研究生教育国 际化、鼓励交叉学科研究、健全考核机制等方面为主要目标研究生培养。研究生导师要求除 了具有优异的学术造诣之外, 还要具备良好的职业道德与素养。但现实是, 由于研究生扩招, 一个导师带十多个研究生的现象并不罕见, 大学教师在利益驱动下正变得愈发浮躁, 有的甚至 抛弃学术尊严和价值立场。另外有的老师随着学术地位的提高和科研项目的增多, 师生面对 面交流的机会越来越少, 对研究生的培养质量造成极大影响。

因而建立严格的导师遴选与考评机制, 打造品德与学术双优的师资队伍是我国研究生教育改 革的当务之急。具体来说, 就是要打破导师终身制, 通过科学的考评, 实现导师“可上可下” 的流动性评聘。研究生导师除了要将时间和精力投入到学术和科研中, 还要注重师生之间的 交流。只有创造师生和谐的关系氛围, 才能激发师生创新活力, 产出创新成果, 培养创新人 才。仅注重导师的主导作用, 忽视研究生的主体地位, 导师难免不产生短视行为, 仅将研究 生作为完成其科研工作的劳动力, 不注重对研究生的全面培养; 但过分强调研究生的个性需 求也是不合适的，研究生应该也必须接受全面、正确的指导、教育与管理。

王洁、孙久厚 [11] 提出从导师队伍专业化、完善支持激励系统、学科骨干建设几方面 优化导师队伍建设, 提高培养质量。刘春桃、柳松等 [12]则阐述了导师制功能有效实现的 几个途径: 导师遴选制度、加强行业道德教育、营造和谐的科研环境、改革招生制度。在研 究生培养机制完善中, 导师将承担着“培养更多高素质的创新性人才和创造更多高水平的创 新性成果”的双重任务。

随着研究生规模的日益扩大, 科研范围变得越来越广泛深入, 交叉性和边缘化学科逐步 
发展, 而且创新性成果很多产生在多学科的交叉点上, 仅靠导师一人指导研究生就显得越来 越力不从心。为保证培养出创新研究能力强的应用型人才, 可以建立不同领域的双向导师组 合。校内导师虽然理论功底深厚和指导经验丰富, 但对企业中各部门实际问题不一定熟悉, 他们主要负责学术指导; 而校外导师长期从事实践工作, 对本部门的技术问题有深刻的认识, 他们主要负责提高研究生的工程实践能力。综上所述, 随着社会的发展, 在研究生教育培养 规模大幅提高, 学位类型、培养模式日趋多样条件下, 导师自身定位、导师培养作用应进一 步加强, 形成既符合教育人才培养规律又适应当前阶段我国研究生培养现状的研究生导师笁 选指标体系, 将是今后培养模式改革、导师制理论发展亟待重点研究的领域。

\section{6 结语}

目前, 我国研究生培养体系已基本形成, 其培养目标是满足国家对高水平应用型人才的 需要, 应用型研究生的培养已经成为我国研究生教育的重要组成部分。当前, 我国研究生教 育已进入全面提高培养质量的新阶段。在顺应社会发展需求为改革主线的前提下, 研究生培 养模式的改革尤其是应用型研究生培养模式的改革还有待进一步深化。相比国外发达国家的 应用型人才培养我国的专业学位教育有些落后, 从应用型研究生培养方案的灵活性到培养方 式的多样化, 从社会的参与到行业及企业进入高校共同制订培养方案以至通过联合培养达到 双赢等, 我国的专业学位教育还任重道远。在肯定我国研究生培养模式改革成效的同时, 进 一步了解各行业领域对应用型人才的培养需求并灵活调整应用型研究生的培养方案及培养 方式, 紧跟社会经济展步伐, 积极与国外的专业学位教育相对接, 早日形成具有自身特色的 研究生培养模式, 是我国应用型研究生培养的努力方向。

\section{致谢}

*基金资助：感谢辽宁科技大学研究生教育创新计划项目” 基于材料加工专业特色研究 生创新人才培养的研究与实践 “资助。

\section{References}

[1] "Outline of the National Medium and Long Term Educational Reform and Development Plan.2010-07-29. http://news.xinhuanet.com/edu/2010-07/29/c_12389320_2.htm.

[2] Shuang Y., Jun K., Liang Z., et al. "Exploration and Practice on the Reform of Postgraduate Training Mode in China.’The Postgraduate Education.2014.1(19):1-5.

[3] Tiequn C., Lixia X., shengli X. "Exploration and practice of "Coherence type" training mode of graduate students.” Graduate Degree and Education”, 2006,(5):58-61.

[4] Xiaoqiu W., Dongxia S., Zhiwei A. "In Order to Improve the Quality of Training as the core, to promote the reform of postgraduate training mechanism.”, Graduate Degree and Education, 2009,(4):7-10.

[5] Wei Y., et al., "Theoretical Thinking and Practical Exploration on the Reform of Postgraduate Training Mechanism.”, Graduate Degree and Education, 2009,(4):1-6.

[6] Chenguang Yang., "Regulations of the People's Republic of China on Academic Degrees -The 30 Anniversary of the Implementation of the Review.”www.jyb.cn, China Education News, 2011.2.15.

[7] Zhenyun F., Yusong Z.,’Discussion on "Chongqing University mode" of innovation practice base of graduate students." Research on Higher Education in China, 2004,(5):37-39.

[8] Jing X., Jun Z., "Exploration and Thinking on the Construction of Graduate Innovation Experiment Center.” Research on Higher Education in China, 2004,(6):36-38. 
[9] Pinqi X., Ju J., Yan W.,’Innovative Ideas, Based on Local, Faced to the World, the Exploration on Internationalization of Graduate Education.” Graduate Degree and Education, 2013,10:53 $-56$.

[10] Gang H., Xiaoyang C., "Understanding and Thinking on the Cultivation of Cross Disciplinary Graduate Students.” Graduate Degree and Education, 2005， （12） : 20-23.

[11] Bin F., Wei Z., He Y., Hongzhi T., "Current situation and Reflection on the innovation of postgraduate training mode in China.”Journal of Chongqing College of Education, 2012, 25(2):104-108.

[12] Chuntao L., Song L., "The function of Tutor in the New Mechanism of Graduate Student Training and the Way to Realize it.” Education Exploration, 2009,(11):96-98. 